\title{
Experimental studies to evaluate the immunomodulatory and anti-inflammatory potential of optimized polyherbal preparations in experimental model of asthma
}

\author{
Maaz Naqvi, Nishant Rai, Kavita Gulati* and Arunabha Ray \\ Department of Pharmacology, Vallabhbhai Patel Chest Institute, University of Delhi, Delhi-110 007, India
}

\begin{abstract}
The study assessed the effect of standardized optimized formulation of UNIM-352, a polyherbal preparation used in the traditional Unani system of medicine in experimental model of bronchial asthma. Wistar Rats (200-250g) were sensitized with ovalbumin adsorbed to aluminium hydroxide. After sensitization, rats were treated orally for 14 days with either of UNIM-352, optimized preparation of UNIM -352 (OP-1, OP-2, OP-3, OP-4) or positive control, and prednisolone in separate groups. The rats were challenged with OVA on $14^{\text {th }}$ day and after $24 \mathrm{~h}$ of challenge, they were anesthetized and bronchoalveolar lavage (BAL) were collected for the assays of IL-4, IgE, eosinophils and neutrophils cell counts. The results showed that both doses of UNIM-352 significantly reduced the levels of IgE and IL-4 in BAL fluid as compared to OVA sensitized and challenged control group. Similarly, both doses OP 1 and OP 3 treated rat significantly reduced levels of IL-4 which was comparable to UNIM-352 in dose dependent manner. Further, optimized preparations of UNIM-352 (OP-1, OP-2, OP-3 and OP-4) at 200 and 400 mg/kg showed reduced number of eosinophils and neutrophils in BAL fluid vs control group. The results were comparable with the standard drug; prednisolone. UNIM-352 and its optimized preparations differentially reduced the eosinophils and neutrophils counts, the effector inflammatory cells in asthma, which was accompanied with the reduction in levels of IgE and IL-4 in BAL fluid suggesting their anti-inflammatory and immunomodulatory effects. This was comparable to the positive control, prednisolone in experimental model of asthma. This relative potential of various optimized preparations of this polyherbal drug in reducing/controlling the airway inflammation associated with bronchial asthma has been discussed.
\end{abstract}

\section{Introduction}

Asthma is a chronic inflammatory disease defined by airway inflammation, reversible airway obstruction and airway hyperresponsiveness [1]. The inflammation of airway involves the activation of inflammatory and structural cells responsible for synthesis and release of inflammatory mediators which are responsible for the pathophysiology of asthma. Activation of mast cells, macrophages, eosinophil and neutrophil leads to release of pro-inflammatory cytokines (TNF- $\alpha$ ), Th2 type cytokines (IL-4) and IgE antibody production. Activated inflammatory cells like macrophages and eosinophil also produce reactive oxygen species (ROS) leading to oxidative stress [2-4].

Bronchodilators ( $\beta 2$ agonist) and anti-inflammatory agents (corticosteroids) are the drug of choice for the treatment of asthma. Corticosteroids have long been used as the main therapeutic drugs for asthma [5]. However, the limitation of available pharmacotherapy is that these drugs provide only symptomatic treatment which is usually accompanied with adverse effects. Additionally, prolonged use of corticosteroids may result in steroid resistance [6]. Hence, phytopharmaceuticals and traditional herbal preparation could be a choice which possesses potential to treat such conditions with minimal side effects.

Traditional herbal medicine has a history of thousands of years and is still widely used. The evolution of traditional herbal medicine is based on observations and practical experience accumulated from millions of practitioners for thousands of years. Since traditional herbal medicine does not have its own history of scientific development, there is little scientific research conducted on the safety of herbal formulation. Herbal medicines have often been provided to humans without scientifically rigorous toxicity testing [7-12]. The herbal drugs used in Indian traditional system of medicine viz. Ayurveda, Unani, Homeopathy, Siddha possess a great potential to cure various disease. These herbal drugs are considered to be relatively safe because of natural origin. UNIM-352 is a polyherbal Unani formulation, which has been clinically used in India for the treatment of bronchial asthma $[13,14]$. UNIM-352 contains six different herbal ingredients and all are well known traditional medicines, viz. Linum usitatissimum, Trigonella foenum-graecum, Allium sativum, Strychnos potatorum, Caesalpinia bonducella, and Pongamia glabra. Previous studies showed that UNIM-352 has anti-inflammatory, immunomodulatory effects in the experimental model of bronchial asthma [15].

Polyherbal formulations without any upper limit of ingredients are allowed only in some countries, whereas, in Europe, US etc. formulations with up to 3-4 plants only can be used. So, this effective and validated formulation can achieve global usage only if its ingredients are brought down without affecting its efficacy and safety. Therefore, in the present study an attempt has been made to optimize UNIM 352 by comparing the efficacy and safety of the original six ingredients with the new optimized preparations (OP) with successive elimination of 1 to 3 ingredients deemed less important in light of available information.

*Correspondence to: Kavita Gulati, Department of Pharmacology, Vallabhbhai Patel Chest Institute, University of Delhi, Delhi-110 007, India

Key words: bronchial asthma, UNIM-352, IL-4, immunomodulatory, optimized preparations of UNIM-352

Received: May 28, 2018; Accepted: June 06, 2018; Published: June 25, 2018 
Naqvi M (2018) Experimental studies to evaluate the immunomodulatory and anti-inflammatory potential of optimized polyherbal preparations in experimental model of asthma

\section{Materials and methods}

\section{Experimental animals}

Wistar rats, weighing $180-220 \mathrm{~g}$ were used in the present study. They were housed in polyacrylic cages and kept in standard controlled room with natural light and dark cycle. Rats were fed with standard food pellets and water ad libitum. The experimental protocol was approved by Institutional Animal Ethics Committee (IAEC/7/2015) and the guidelines of Indian National Science Academy, New Delhi were followed for care and safety of animals in scientific research

\section{Drugs and chemicals}

UNIM-352 and optimised preparations of UNIM-352 used in the present study, are standardized formulations prepared and supplied by Central Research Institute of Unani Medicine (CRIUM), Hyderabad, under the auspices of Central Council for Research in Unani Medicine (CCRUM), Ministry of AYUSH, Government of India, New Delhi.

UNIM-352 contains 6 ingredients: Linum usitatissimum L [16] (1g), Trigonella foenum-graecum L (2g), [17] Allium sativum L (3.5g), [18] Strychnos potatorum L (7g), [19] Caesalpinia bonducella Fleming (1g), [20] Pongamia glabra Vent (1g), [21] and Honey (q.s.) in 20g of preparation.

Optimised preparation-1(OP-1) contains 3 ingredients: Strychnos potatorum L, Trigonella foenum-graecum L, Pongamia glabra Vent, Honey.

Optimised preparation-2(OP-2) contains 4 ingredients: Strychnos potatorum L, Trigonella foenum-graecum L, Pongamia glabra Vent, Allium sativum L, and Honey.

Optimised preparation-3(OP-3) contains 4 ingredients: Strychnos potatorum L, Trigonella foenum-graecum L, Pongamia glabra Vent, Linum usitatissimum L, and Honey.

Optimised preparation-4(OP-4) contains 4 ingredients: Strychnos potatorum L, Trigonella foenum-graecum L, Pongamia glabra Vent, Caesalpinia bonducella Fleming, and Honey.

Prednisolone, and Ovalbumin (OVA) were purchased from M/s. Sigma Aldrich. Rat IgE and IL-4 Elisa kit were purchased from QAYEE-BIO (Cat no-QY-E11192) and Diaclone (Cat no-8650.020.096) respectively.

\section{Experimental groups and treatment}

Wistar rats were divided randomly into four groups each containing six rats: (i) Normal group: Rat were treated only with distilled water (vehicle) orally for 14 days (ii) Control group: rats were immunized with OVA and challenged on day 14 and treated with distilled water orally; (iii) and (iv) UNIM-352(200) and (400) groups: rats were immunized and challenged with OVA and treated with UNIM-352 at the dose of 200 or $400 \mathrm{mg} / \mathrm{kg}$ from day 1 to 14, orally (v) and (vi) Optimised Preparation-1 (OP-1): rats were immunized and challenged with OVA and treated orally with OP-1 at the dose of 200 or $400 \mathrm{mg} / \mathrm{kg}$; (vii) and (viii) Optimised preparation-2 (OP-2): rats were immunized and challenged with OVA and treated orally with OP-2 at the dose of 200 or $400 \mathrm{mg} / \mathrm{kg}$; (ix) and (x) Optimised preparation-3, (OP-3): rats were immunized and challenged with OVA and treated orally with OP-3 at the dose of 200 or $400 \mathrm{mg} / \mathrm{kg}$; (xi) and (xii) Optimised preparation-4, (OP-4): rats were immunized and challenged with OVA and treated orally with OP-4 at the dose of 200 or $400 \mathrm{mg} / \mathrm{kg}$; (xiii) Prednisolone group: rats were immunized and challenged with OVA and treated orally with prednisolone at the dose of $10 \mathrm{mg} / \mathrm{kg}$.

\section{Immunization and challenge protocol}

All rats in each group except Normal group were immunized and challenged with OVA according to the procedure described by Kwasniewski, et al. (1998) [22]. Briefly, rats were sensitized by intraperitoneal injection of OVA (10 mg per rat) emulsified with $10 \mu \mathrm{g}$ of aluminium hydroxide in $0.5 \mathrm{ml}$ of normal saline on the first day of the study. After 14 days of sensitization, animals were challenged with $1 \mathrm{mg}$ of ovalbumin.

\section{BAL fluid collection}

After 24 hrs of OVA challenge, all animals were anesthetized, and BAL fluid was collected. BAL fluid was collected by lavaging the lung through tracheal cannula with $0.9 \%$ sodium chloride solution and centrifuged at $1500 \mathrm{rpm}$ at $4^{\circ} \mathrm{C}$ for $10 \mathrm{~min}$ and supernatant recovered and stored at $-80^{\circ} \mathrm{C}$ for the assay of IL-4 cytokine [22]. The precipitated pellets were resuspended in $100 \mu \mathrm{l}$ of normal saline. Eosinophil and neutrophil counts in BAL fluid were carried out using Neubauer chamber.

\section{Assay for IL-4 Levels}

BAL fluid samples were assayed for the levels of IL-4 using commercially available ELISA Kits. Briefly the cytokine assays were performed using solid phase sandwich ELISA. Antigen and biotinylated polyclonal antibody specific for IL- 4 were added to the microtitre plate wells whose walls were precoated with polyclonal antibody specific for IL-4 and incubated for specific period. The HRP conjugated streptoavidin was added and incubated. Finally, TMB substrate solution was added to induce a coloured reaction product. Then again incubate in the dark for 10-20 min at room temperature, avoid direct exposure to light. The enzyme substrate solution was stopped by adding H2So4. The absorbance of the coloured product was measured using softwarebased microplate reader (ECIL) at $450 \mathrm{~nm}$ and results were expressed in $\mathrm{pg} / \mathrm{ml}$.

\section{Assay for IgE levels}

BAL fluid samples were assayed for levels of IgE using commercially available enzyme-linked immunosorbent assay (ELISA) kits. These cytokine assays were performed using double antibody sandwich ELISA. The microtitre plate provided is precoated with monoclonal antibody specific to Immunoglobulin E (IgE). Samples were added to wells and after incubation OVA s IgE secondary antibody labelled with biotin was added. Streptovidin-HRP was added to wells in order to form immune complex and was then incubated. Chromogenic solution $\mathrm{A}$ and $\mathrm{B}$ were added to develop colour and the reaction was stopped by using a stop solution. The absorbance of colored product was measured using software-based microplate reader at $450 \mathrm{~nm}$ and results were expressed in $\mathrm{ng} / \mathrm{ml}$.

\section{Statistical analysis}

Data are expressed as mean \pm SEM and analyzed by using one-way ANNOVA followed by tukey's test. A P value of $<0.05$ was used as the level of significance in all statistical tests.

\section{Results}

\section{Effects of UNIM-352 and optimized preparations of UNIM- 352 on IgE in BAL fluid}

Assay for IgE showed that sensitization and challenge with OVA resulted in significant increase in the level of IgE in BAL fluid, as compared to the Normal group. UNIM-352(200and $400 \mathrm{mg} / \mathrm{kg}$ ) and 

model of asthma

both the doses of optimized formulations of UNIM-352 (OP-1, OP-2, OP-3 and OP-4) decreased the level of IgE in BAL fluid, when compared with vehicle treated Control group. UNIM-352, OP-1, OP-2, OP-3 and OP- 4 at dose $200 \mathrm{mg} / \mathrm{kg}$ reduced IgE levels by $60 \%, 81 \%, 63 \%, 73 \%$ and $80 \%$ respectively, as compared to Control. UNIM-352, OP-1, OP-2, OP-3 and OP- 4 at dose $400 \mathrm{mg} / \mathrm{kg}$ reduced IgE levels by $56 \%, 85 \%, 61 \%$, $79 \%$ and $82 \%$ respectively, as compared to Control. The reductions were comparable with the standard drug prednisolone. OP-1 at both the doses significantly reduced the IgE levels in BAL fluid as compared to UNIM-352 (400 mg/kg). Further, OP-4 at the dose of $400 \mathrm{mg} / \mathrm{kg}$ also significantly reduced the IgE levels in BAL fluid vs UNIM-352 $(400 \mathrm{mg} / \mathrm{kg}$ ). Interestingly, the reductions were greater in magnitude as compared to UNIM-352. Overall analysis of the data revealed that the changes in the levels of IgE after various treatment were significantly different across all groups $(\mathrm{p}<0.01)$ and comparisons of individual groups with Control group are shown in Figure 1.

\section{Effects of UNIM-352 and optimized preparations of UNIM-} 352 on Eosinophils and Neutrophils in BAL fluid

Effects of optimized formulations of UNIM-352 were assessed on eosinophil cell counts in BAL fluid in OVA sensitized and challenged rats. The results showed that sensitization and challenge with OVA resulted in significant increase in the number of eosinophil cells in BAL fluid, as compared to the Normal group (not sensitized and challenged with OVA). UNIM-352 and Optimized preparations of UNIM-352 differentially reduced the number of eosinophil cells at both the dose levels (200 and 400mg) in BAL fluid, when compared with vehicle treated Control group (sensitized and challenged with OVA). UNIM-352, OP-1, OP-2, OP-3 and OP-4 at dose $200 \mathrm{mg} / \mathrm{kg}$ reduced eosinophil counts by $55 \%, 42 \%, 39 \%, 34 \%$ and $33 \%$ respectively, as compared to Control. UNIM-352, OP-1, OP-2, OP-3 and OP-4 at dose $400 \mathrm{mg} / \mathrm{kg}$ reduced eosinophil counts by $70 \%, 55 \%, 60 \%, 57 \%$ and $51 \%$ respectively, as compared to Control. Pre-treatment with the standard drug Prednisolone, markedly suppressed the eosinophil counts in BAL fluid. Analysis of the data revealed that the changes in the number of eosinophil cells after various treatment were significantly different across all groups $(\mathrm{p}<0.01)$ and comparisons of individual groups with Control group are shown in Figure 2.

Similarly, effects of optimized formulations of UNIM-352 were assessed on neutrophil cell counts in BAL fluid in OVA sensitized rats. The results showed that sensitization and challenge with OVA resulted in significant increase in the number of neutrophil cells in BAL fluid, as compared to the Normal group. UNIM-352 and Optimized preparations of UNIM-352 reduced the number of neutrophil cells at both the dose levels (200 and 400mg) in BAL fluid, vs Control group. UNIM-352, OP-1, OP-2, OP-3 and OP- 4 at dose $200 \mathrm{mg} / \mathrm{kg}$ reduced neutrophil counts by $42 \%, 39 \%, 31 \%, 64 \%$ and $56 \%$ respectively, as compared to Control. UNIM-352, OP-1, OP-2, OP-3 and OP-4 at dose $400 \mathrm{mg} / \mathrm{kg}$ reduced neutrophil counts by $56 \%, 60 \%, 50 \%, 68 \%$ and $65 \%$ respectively, as compared to Control. The reductions were comparable with the standard drug Prednisolone. Overall analysis of the data revealed that the changes in the number of neutrophil cells after various treatment were significantly different across all groups $(\mathrm{p}<0.01)$ and comparisons of individual groups with Control group are shown in Figure 3.

\section{Effects of UNIM-352 and optimized preparations of UNIM-} 352 on IL-4 levels in BAL fluid

Assay for IL-4 showed that sensitization and challenge with OVA resulted in significant increase in the level of IL-4 in BAL fluid, as compared to the Normal group. UNIM-352(200and $400 \mathrm{mg} / \mathrm{kg}$ ) and both the doses of optimized formulations of UNIM-352 (OP-1, OP2, OP-3 and OP-4) decreased the level of IL-4in BAL fluid, when compared with vehicle treated Control group. UNIM-352, OP-1, OP-2, OP-3 and OP- 4 at dose $200 \mathrm{mg} / \mathrm{kg}$ reduced IL- 4 levels by $25 \%, 33 \%$, $21 \%, 28 \%$ and $22 \%$ respectively, as compared to Control. UNIM-352, OP-1, OP-2, OP-3 and OP- 4 at dose $400 \mathrm{mg} / \mathrm{kg}$ reduced IL- 4 levels by $39 \%, 50 \%, 30 \%, 49 \%$ and $30 \%$ respectively, as compared to Control. The reductions were comparable with the standard drug prednisolone. OP- 1 and OP-3 at the dose of $400 \mathrm{mg} / \mathrm{kg}$ significantly reduced the IL- 4 levels in BAL fluid as compared to UNIM-352 (200 mg/kg). Overall analysis of the data revealed that the changes in the levels of IL-4 after various treatment were significantly different across all groups $(\mathrm{p}<0.01$ and comparisons of individual groups with Control group are shown in Figure 4.

\section{Discussion}

Asthma is a chronic inflammatory disease which is characterized by eosinophilic airway inflammation, mucus hyper-secretion, and bronchial hyper-responsiveness. Its pathophysiology is regulated by the complex interactions between cellular and humoral components. The pharmacotherapy depends on controllers (corticosteroids) and relievers (bronchodilators) agents and life-long therapy is required for management of bronchial asthma, once the patient is diagnosed. Though significant incidence of adverse effects related to these drugs has been a key area of concern, the increasing incidence of refractoriness to conventional forms of therapy has further complicated the problem $[5,6]$. Therefore, it is the need of time to focus extensively on alternative

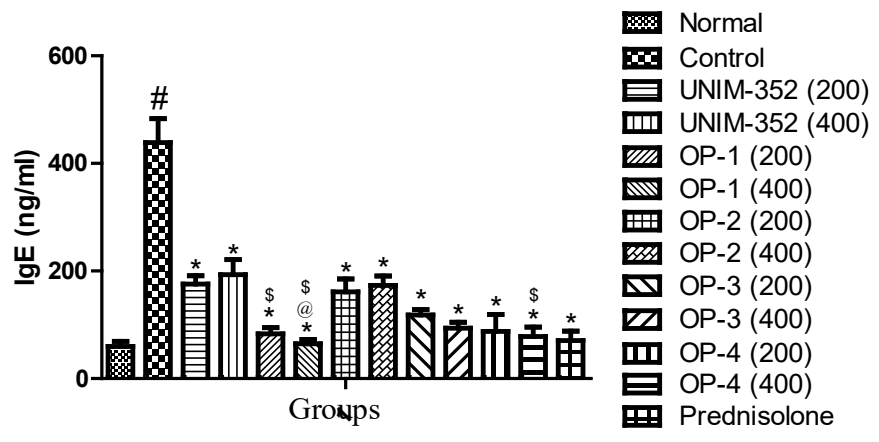

Figure 1. Effects of UNIM-352 and optimized preparations of UNIM-352 on IgE levels in BAL fluid of OVA immunized and challenged rats. Data are expressed as Mean \pm SEM. $\# p<$ 0.01 vs normal group; ${ }^{*} \mathrm{p}<0.05$ and $* * \mathrm{p}<0.01$ vs control group; ${ }^{\circledR} \mathrm{p}<0.05$ vs UNIM-352 $(200 \mathrm{mg} / \mathrm{kg})$ and ${ }^{\mathrm{s}} \mathrm{p}<0.05 \mathrm{vs}$ UNIM-352 $(400 \mathrm{mg} / \mathrm{kg})$

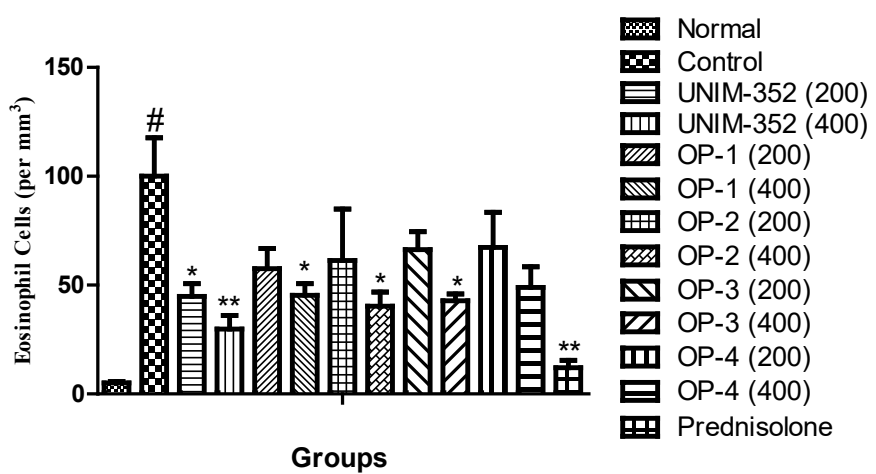

Figure 2. Effects of UNIM-352 and optimized preparations of UNIM-352 on eosinophil counts in BAL fluid of OVA immunized and challenged rats. Data are expressed as Mean \pm SEM. ${ }^{*} \mathrm{p}<0.01$ vs Normal group; $* \mathrm{p}<0.05$ and $* * \mathrm{p}<0.01$ vs Control group 


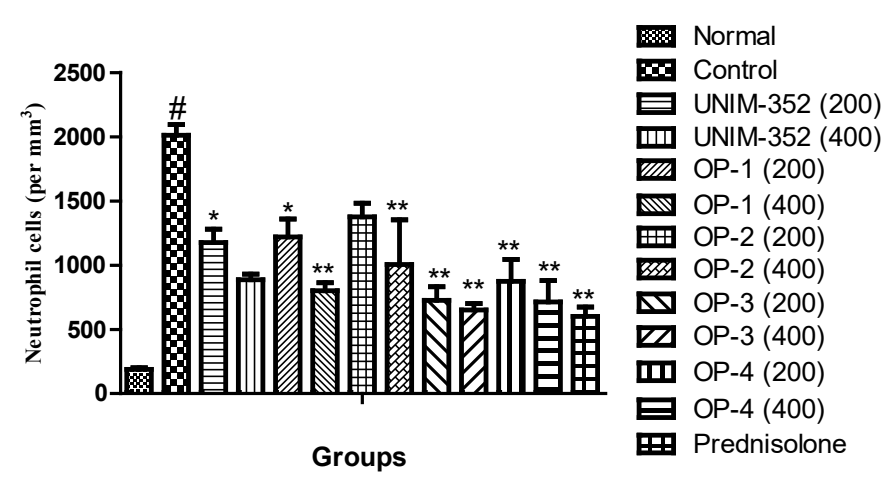

Figure 3. Effects of UNIM-352 and optimized preparations of UNIM-352 on neutrophil counts in BAL fluid of OVA immunized and challenged rats. Data are expressed as Mean \pm SEM. ${ }^{*} \mathrm{p}<0.01$ vs normal group; ${ }^{*} \mathrm{p}<0.05$ and ${ }^{* *} \mathrm{p}<0.01$ vs control group

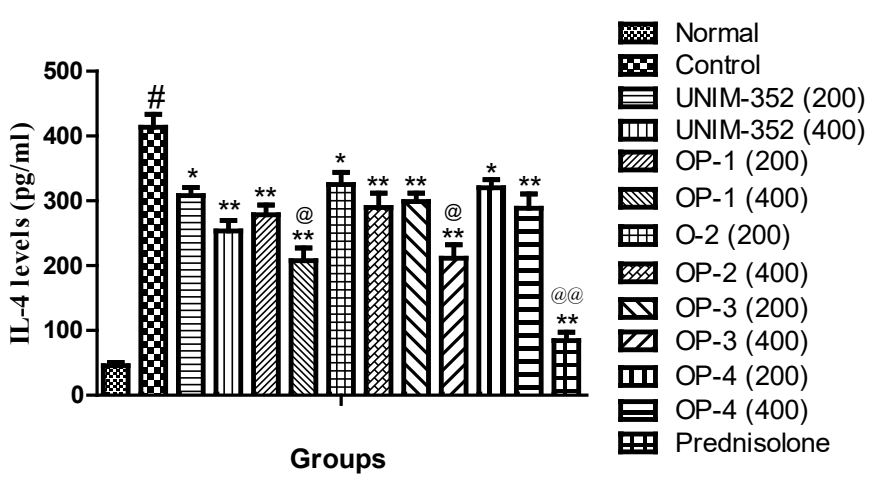

Figure 4. Effects of UNIM-352 and optimized preparations of UNIM-352 on IL-4 levels in BAL fluid of OVA immunized and challenged rats. Data are expressed as Mean $\pm \mathrm{SEM}$. ${ }^{\#} \mathrm{p}<0.01$ vs normal group; ${ }^{*} \mathrm{p}<0.05$ and ${ }^{* *} \mathrm{p}<0.01$ vs control group; ${ }^{\circledR} \mathrm{p}<0.05$ and ${ }^{\circledR} \mathrm{p}<<$ 0.01 vs UNIM-352 $(200 \mathrm{mg} / \mathrm{kg})$.

strategies for rational management of the disorder. Medicinal plants and plant derived products have long been recognized as major resources for alternative therapy for several disease states. The World Health Organization also encourages, recommends and promotes traditional or herbal drugs in National Health Care Programmes because of their easy availability, low cost, safety and the faith of people in such remedies. Although, Indian traditional medicine like Ayurveda and Unani have several formulations to cure bronchial asthma based on clinical experience but, there is need for scientific validation of such claims before recommendation for complimentary therapy.

UNIM-352 is one such polyherbal Unani preparation with documented clinical use in patients of bronchial asthma. Our pilot clinical study has shown that UNIM-352 improves the efficacy and safety of conventional treatment of bronchial asthma in modern medicine and thus, could be considered as viable alternatives or an adjunct for pharmacotherapy [23-25]. Acute and sub-acute toxicity studies with UNIM-352 and its optimized prepations have shown that it is safe up to the dose of $2000 \mathrm{mg} / \mathrm{kg}$ and showed no toxicity sign as compared to that in control rats.

The inflammatory process in asthma involves antigen interaction and sustained infiltration and activation of many inflammatory cells including eosinophils, neutrophils, lymphocytes, basophils and macrophages, followed by initiation and release of various proinflammatory mediators and cytokines [26-28]. Th2 cells are the key orchestrators of this inflammation, which initiates and propagate inflammation by the release of cytokines, IgE, IL-4. These are well known mediators, and a potent modulator of immune and inflammatory response resulting in influx of neutrophils and eosinophils as well as bronchial hyperreactivity.

Inhibition of inflammatory responses mediated through inflammatory cells and their cytokines, is a basic therapeutic aim in treatment of asthma. Present study showed significant suppression of IgE responses by administration of optimized preparations of UNIM352 in BAL fluid samples as compared to control. Inflammation and infiltration of the airways with eosinophils and neutrophils is the characteristic feature of asthma and in most of the phenotype is accompanied with increased levels of these cells in tissue, blood and bronchoalevolar lavage (BAL) fluid in general and has direct correlation with disease severity [29]. The result of our experiments showed that treatment with optimized formulations of UNIM-352 (OP-1, OP-2, OP-3 and OP-4) and UNIM-352 alone in both dose levels (200 and $400 \mathrm{mg} / \mathrm{kg}$ ) reduced the number of eosinophil and neutrophil cells in BAL fluid of ovalbumin immunized and challenged rats. Prednisolone $(10 \mathrm{mg} / \mathrm{kg})$ treatment, which acted as positive control group, also decreased the number of eosinophils and neutrophils cells in separate group of rats indicating the comparability of our data.

IL-4 plays an important role in the development of allergic airway inflammation. Patients with bronchial asthma have increased IL-4 protein levels in serum and bronchoalveolar lavage fluid [30]. The results of our study showed that IL-4 levels were suppressed in BAL fluid in ovalbumin immunized and challenged rats after treatment with optimized formulations (OP-1, OP-2, OP-3 and OP-4) and UNIM352. Interestingly, the reductions were more marked with OP-1 and OP-3 preparations as compared to UNIM-352, which may envisage better efficacy of these optimized versions. Further, results of OP-1 on suppression of IgE levels also showed better efficacy as compared to positive control prednisolone. However, detailed studies on various cellular and molecular markers of asthma are required to confirm better efficacy of OP-1 and OP-3 as compared to UNIM-352.

Taken together, it can be concluded that UNIM-352 and its optimized preparations may act by preventing infiltration of the eosinophils and neutrophils (the effector cells in asthma) and reducing the levels of IgE andTh-2 cytokine, IL-4 which are responsible for release of various inflammatory mediators, thus contributing to the therapeutic benefits observed in patients of bronchial asthma.

\section{Acknowledgements}

The financial support from Indian Council of Medical Research (ICMR), Government of India, New Delhi is gratefully acknowledged. The authors also acknowledge the Central Council for Research in Unani Medicine (CCRUM) for the supply of UNIM-352 and its optimized formulations.

\section{References}

1. Shifren A, Witt C, Christie C, Castro M (2012) Mechanisms of remodeling in asthmatic airways. J Allergy (Cairo) 2012: 316049. [Crossref]

2. Behera D, Sehgal IS (2015) Bronchial asthma - issues for the developing world. Indian J Med Res 141: 380-382. [Crossref]

3. Brightling CE, Symon FA, Birring SS, Bradding P, Pavord ID, et al. (2002) TH2 cytokine expression in bronchoalveolar lavage fluid $\mathrm{T}$ lymphocytes and bronchial submucosa is a feature of asthma and eosinophillic bronchitis. J Allergy Clin Immunol 110: 899-905. [Crossref]

4. Busse WW, Rosenwasser LJ (2003) Mechanisms of asthma. J Allergy Clin Immunol 111: 799-807. [Crossref]

5. Wenzel SE, Covar R (2006) Update in asthma 2005. Am J Respir Crit Care Med 173 698-706. [Crossref] 
6. Barnes PJ (2004) Corticosteroid resistance in airway disease. Proc Am Thorac Soc 1: 264-268. [Crossref]

7. Mukherjee PK, Wahile A (2006) Integrated approaches towards drug development from Ayurveda and other Indian system of medicine. J Ethnopharmacol 103: 25-35. [Crossref]

8. Umrani RD, Agarwal DS, Paknikar KM (2013) Antidiabetic activity and safety assessment of Ayurvedic medicine, Jasada bhasma (zinc ash) in rats. Indian J Exp Biol 811-822. [Crossref]

9. Joshi R, Reeta KH, Sharma SK, Tripathi M, Gupta YK (2015) Panchagavya Ghrita an Ayurvedic formulation attenuates seizures cognitive impairement and oxidative stress in pentylenetetrazole induced seizures in rats. Indian J Exp Biol 53: 446-451. [Crossref]

10. Aggarwal A, Singla SK, Tandon C (2014) Urolithiasis: Phytotherapy as an adjunct therapy. Indian J Exp Biol 52: 103-111. [Crossref]

11. Girish C, Koner BC, Jayanthi S, Rao KR, Rajesh B, et al. (2009) Hepatoprotective activity of six polyherbal formulation in $\mathrm{CCl} 4$ - induced liver toxicity in mice. Indian $J$ Exp Biol 47: 257-263. [Crossref]

12. Manik S, Gauttam V, Kalia AN (2009) Antidiabetic and antihyperlipidemic effect of allopolyherbal formulation in OGTT and STZ- induced diabetic rat model. Indian $J$ Exp Biol 51: 702-708. [Crossref]

13. Guhathakurta S, Gulati K, Rai N, Banerji BD, Jamil SS, et al. (2012) An experimental study to evaluate the anti-inflammatory and immunomodulatory effects of UNIM -352, a polyherbal preparation for bronchial asthma. Med Plant Res 3: 3-6.

14. Guhathakurta S, Gulati K, Jamil SS, Vijayan VK, Ray A, et al. (2012) Experimental studies on the mast cell stabilizing and bronchorelaxant effect of UNIM-352, a polyherbal Unani preparation with therapeutic potential in bronchial asthma. Med Plant 483.

15. Rai N., Ray A, Jamil SS, Gulati K (2015) Cellular and molecular mechanisms of action of polyherbal preparation UNIM-352 in experimental models of bronchial asthma. Indian J Exp Biol 53: 625-631. [Crossref]

16. Kinniry P, Amrani Y, Vachani A, Solomides CC, Arguiri E, et al. (2006) Dietary Flaxseed supplementation ameliorates Inflammation and oxidative tissue damage in experimental models of acute lung injury in mice. J Nutr 136: 1545-1551. [Crossref]

17. Bae MJ, Shin HS, Choi DW, Shon DH (2012) Antiallergic effect of Trigonella foenum -graecum L. extracts on allergic skin inflammation induced by trimellitic anhydride in BALB/c mice. J Ethnopharmacol 144: 514-522. [Crossref]
18. Fehri B, Ahmad MK, Aiache JM (2012) The relaxant effect induced by Allium sativum L. extracts on allergic skin inflammation induced by trimellitic anhydride in BALB/c mice. J Ethnopharmacol 144: 514-522.

19. Patil UJ, Savali AS, Jirankali MC (2011) Antianaphylactic and mast cell stabilization activity of Strychnos potatorum Linn. Seed. Pharmacognosy Res 3: 208-213. [Crossref]

20. Gayaraja S, Shinde S, Agarwal SL (1978) Anti-asthmatic properties of Caesalpinia bonducella leaves. Indian J Physiol Pharmacol 10: 86.

21. Singh RK, Pandey BL (1996) Anti-inflammatory activity of seed extract of Pongomia pinnata in rat. Indian J Pharmacol 40: 355-358. [Crossref]

22. Kwasniewski FH, Tavares de Lima W, Bakhle YS, Jancar S (1998) Impairement in connective tissue mast cell degranulation in spontaneously hypersensitive rats: stimulus dependent resistance. Br J Pharmacol 124: 772-776. [Crossref]

23. Gulati K, Guhathakurta S, Rai N, Jamil SS, Siddiqui MK, et al. (2012) Translationa studies with a polyherbal agent in bronchial asthma: a reverse pharmacology approach, In: Translational Research in New Drug Development (Vidyanilyam Prakashan, Delhi) 255

24. Nirmala Devi MK, Kazmi MH, Ahmad G, Yadav PK, Siddiqui KM, et al. (2010) Retrospective study of clinical exacerbations and eosinophillic inflammation in patients with stable, well controlled asthma treated with Unani coded drugs UNIM-352 and UNIM -353. Hippocratic J Unani Med 5: 1.

25. Kazmi MH, Qureshi MA, Devi N, Khan P, Bano (2009) H Effect of Unani compound coded drug (UNIM-352) on zeequm nafs (bronchial asthma)- a preliminary clinical study. Hippocratic J Unani Med 4: 15.

26. Lee MY, Seo CS, Ha H, Jung D, Lee NH, et al. (2010) Protective effects of Ulumus davidiana var. japonica against OVA - induced murine asthma model via upregulation of heme oxygenase-1. J Ethnopharmacol 130: 61-69. [Crossref]

27. Amin K, Ludviksdottri D, Janson C, Nettelbladt O, Bjornsson E, et al. (2000) Inflammation and structural changes in the airways of patients with atopic and nonatopic asthma. BHR Group. Am J Respir Crit Care Med 162: 2295-2301. [Crossref]

28. Maddox L, Schwartz DA (2002) The pathophysiology of asthma. Annu Rev Med 53: 477-498. [Crossref]

29. Fahy JV (2009) Eosinophilic and neutrophilic inflammation in asthma: insights from clinical studies. Proc Am Thorac Soc 6: 256-259. [Crossref]

30. Ramshaw HS, Woodcock JM, Bagley CJ, McClure BJ, Hercus TR, et al. (2001) New approaches in the treatment of asthma. Immunol Cell Biol 79: 154-159. [Crossref]

Copyright: (C2018 Naqvi M. This is an open-access article distributed under the terms of the Creative Commons Attribution License, which permits unrestricted use, distribution, and reproduction in any medium, provided the original author and source are credited. 